\title{
Multiple Myeloma Complicated with Streptococcal Endocarditis Successfully Treated by Mitral Valve Replacement
}

\author{
Shigeru Fukuzawa, Shun Ozawa, Kazuhiro ShIMAda and Makoto KatagiRI
}

\begin{abstract}
A 63-year-old male patient with multiple myeloma developed congestive heart failure due to streptococcus endocarditis prior to the initiation of chemotherapy. Doppler echocardiographical examination revealed the presence of a large vegetation on the anterior mitral leaflet as well as the association of severe mitral regurgitation. Surgical repair (mitral valve replacement) was urgently undertaken and the postoperative course resulted in uneventful recovery. In immunodeficient patients with such a streptococcus sepsis, the possibility of infectious endocarditis should be taken into consideration and proper management is mandatory in these circumstances.
\end{abstract}

(Internal Medicine 33: 13-17, 1994)

Key words: biphasic infection in myeloma, doppler echocardiogram, immunodeficiency

\section{Introduction}

Multiple myeloma is characterized by neoplasm of plasma cells in bone marrow. Plasma cell neoplasm causes an increase of M-protein in the serum and a decrease in the serum level of normal immunoglobulin. As a consequence bacterial infections often complicate the critical course of multiple myeloma. The increased susceptibility to infection in these patients has been related to impaired antibody production. Previously the most frequently reported infection has been pneumonia by streptococcus pneumoniae (1). Additionally recent studies indicated that the bacterial spectrum appears to have shifted from gram-positive to gram-negative bacterias $(2,3)$. Infections have been the leading cause of morbidity and mortality in patients with multiple myeloma. Despite the common occurrence of bacteremias, infective endocarditis (IE) is seldom encountered. Here, this is taken into consideration in relation to the inherent immunologic and hematologic abnormalities presenting in plasma cell dyscrasias. A patient with multiple myeloma who developed congestive heart failure due to streptococcal endocarditis, and subsequently underwent mitral valve replacement prior to the initiation of chemotherapy is described in this report.

\section{Case Report}

A 63-year-old man who had a history of fever for 8 weeks and a loss of body weight of $4 \mathrm{~kg}$ was hospitalized for general evaluation. He was noted to have had a systolic murmur and had an episode of pneumonia previously. He had chronic gingivitis for two years. The physical examinations showed blood pressure of $130 / 80 \mathrm{mmHg}$, temperature of $37.6^{\circ} \mathrm{C}$, and regular pulse at $92 / \mathrm{min}$. There was slight anemia but no jaundice. Superficial lymph nodes were not palpable. The cardiac examination at the time of admission revealed apical holosystolic murmur of a grade III/VI radiating to the axilla. No rale was heard in the lung. The abdomen was soft and flat. Neither the liver, spleen nor masses were palpable. There was no evidence of splinter hemorrhages or petechiaes in the extremities. Osler's nodes were present on the dorsal surface of the left toe. Janaway's lesion was absent. The initial chest X-ray was normal with a cardiothoracic ratio (CTR) of $45 \%$ as well as a clear lung field (Fig. 1a). The electrocardiogram was interpreted as sinus tachycardia with a normal axis.

The initial blood count showed a hematocrit of $32.7 \%$, leukocyte count of 10,900 with $12 \%$ of stab and $81 \%$ of segment forms, $6 \%$ of lymphocytes and $1 \%$ of monocytes. Laboratory data included an erythrocyte sedimentation rate (ESR) of 110 $\mathrm{mm} / \mathrm{hr}$. and C-reactive protein (CRP) of $12.0 \mathrm{mg} / \mathrm{dl}$. Serum protein electropheresis displayed monoclonal IgG kappa spikes, quantitation of serum IgG was $3,570 \mathrm{mg} / \mathrm{dl}$. A bone marrow aspiration biopsy showed that the specimen was packed with plasma cells. Other laboratory data on admission included normal liver function, serum creatine $0.8 \mathrm{mg} / \mathrm{dl}$, total protein $7.4 \mathrm{~g} / \mathrm{dl}$, albumin $2.7 \mathrm{~g} / \mathrm{dl}$, and no abnormalities of electrolytes (Table 1). Blood culture at admission grew Streptococcus (S.)

From the Division of Cardiology, Funabashi Municipal Medical Center, Funabashi

Received for publication March 18, 1993; Accepted for publication November 2, 1993

Reprint requests should be addressed to Dr. Shigeru Fukuzawa, the Division of Cardiology, Funabashi Municipal Medical Center, 1-21-1 Kanasugi, Funabashi, Chiba 273 

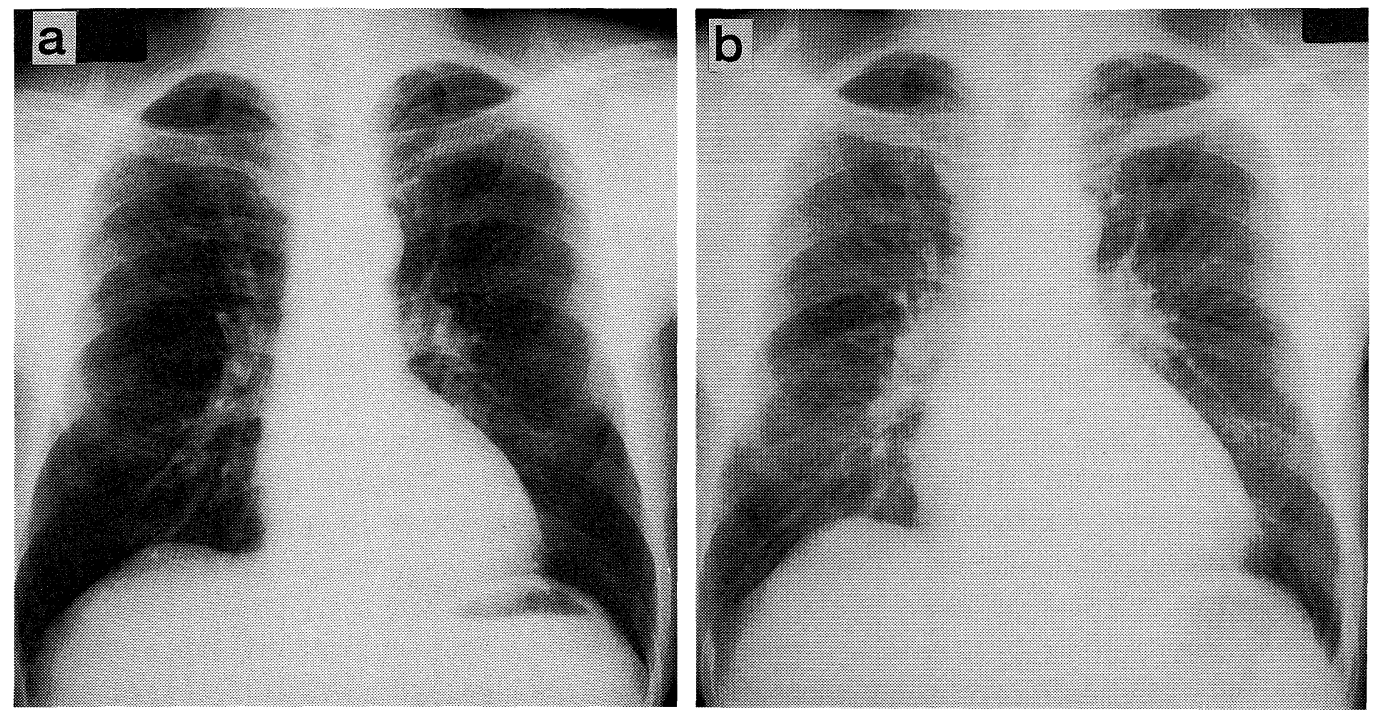

Fig. 1. Chest rentogenogram. (a) On admission, CTR and pulmonary markings were normal. (b) Two months later, marked cardiomegaly and increased pulmonary parenchymal infiltration were revealed.

Table 1. Laboratory Data on Admission

\begin{tabular}{|c|c|c|c|}
\hline \multicolumn{2}{|c|}{ Peripheral blood } & \multicolumn{2}{|c|}{ Blood chemistry } \\
\hline $\mathrm{RBC}$ & $374 \times 10^{4} / \mathrm{mm}^{3}$ & $\mathrm{TP}$ & $7.4 \mathrm{~g} / \mathrm{dl}$ \\
\hline $\mathrm{Hb}$ & $10.6 \mathrm{~g} / \mathrm{dl}$ & Alb & $2.7 \mathrm{~g} / \mathrm{dl}$ \\
\hline $\mathrm{Ht}$ & $32.7 \%$ & Cho & $148 \mathrm{mg} / \mathrm{dl}$ \\
\hline Plat. & $30.5 \times 10^{4} / \mathrm{mm}^{3}$ & AlP & $147 \mathrm{IU} / \mathrm{dl}$ \\
\hline WBC & $10,900 / \mathrm{mm}^{3}$ & $\mathrm{LDH}$ & 326IU/1 \\
\hline Stab & $12 \%$ & ALT & 9IU/l \\
\hline Seg & $81 \%$ & AST & $10 \mathrm{IU} / 1$ \\
\hline Lym & $6 \%$ & BUN & $15 \mathrm{mg} / \mathrm{dl}$ \\
\hline Mono & $1 \%$ & $\mathrm{Crn}$ & $0.8 \mathrm{mg} / \mathrm{dl}$ \\
\hline \multicolumn{2}{|l|}{ Serology } & $\mathrm{Na}$ & $136 \mathrm{mEq} / \mathrm{l}$ \\
\hline ESR & $110 \mathrm{~mm} / \mathrm{hr}$ & $\mathrm{K}$ & $4.0 \mathrm{mEq} / \mathrm{l}$ \\
\hline CRP & $12.0 \mathrm{mg} / \mathrm{dl}$ & $\mathrm{Cl}$ & $101 \mathrm{mEq} / 1$ \\
\hline \multicolumn{2}{|l|}{ Urine } & $\mathrm{P}$ & $2.8 \mathrm{mg} / \mathrm{dl}$ \\
\hline $\mathrm{pH}$ & 6.5 & $\mathrm{Ca}$ & $4.8 \mathrm{mEq} / 1$ \\
\hline Protein & $(-)$ & $\mathrm{Mg}$ & $1.9 \mathrm{mEq} / \mathrm{l}$ \\
\hline Glucose & $(-)$ & \multicolumn{2}{|c|}{ Serum immunoglobulin } \\
\hline Ketone & $(-)$ & $\operatorname{IgG}$ & $3,570 \mathrm{mg} / \mathrm{dl}$ \\
\hline \multirow{2}{*}{\multicolumn{2}{|c|}{ Bence-Jones heat test $(-)$}} & $\operatorname{IgA}$ & $20 \mathrm{mg} / \mathrm{dl}$ \\
\hline & & IgM & $63 \mathrm{mg} / \mathrm{dl}$ \\
\hline
\end{tabular}

salivarius.

Echocardiography revealed slightly enlarged left ventricle and the presence of a vegetation at the anterior leaflet of mitral valve. The anterior leaflet prolapsed to the left atrium and the size of vegetation was $1 \times 1.8 \mathrm{~cm}$ in diameter. Color flow doppler showed a moderate degree of mitral regurgitation (Fig. 2a). He was treated with intravenous administration of aminobenzilpenicillin, and subsequently ESR and CRP were improved during the period of 6 weeks (Fig. 3).

However two months later, the patient developed a holosystolic murmur with the complaint of dyspnea on effort. The chest X-ray revealed marked cardiomegaly (CTR 54\%) and increased pulmonary parenchymal infiltrations (Fig. 1b). Doppler echocardiogram demonstrated a large vegetation $(1.2 \times 2.0 \mathrm{~cm})$ at the anterior leaflet of the mitral valve as well as the presence of severe mitral regurgitation. Although the size of the left ventricle was dilated larger than at the time of admission, fractional shortening was not changed (Fig. 2b). The patient was placed strictly on diuretics, vasodilators and digitalis therapy. Yet dyspnea on effort persisted. He was scheduled for urgent surgery due to worsening cardiac failure.

At surgery, in addition to the expected mitral valve prolapse and vegetation, a perforation of the anterior leaflet was identified (Fig. 4). A Carpentier-Edwards mitral valve prosthesis was implanted. Postoperatively antibiotic therapy with aminobenzilpenicillin was continued to be administrated and he recovered with an uneventful course. One month after the surgery, the definitive treatment for his original disease of multiple myeloma was initiated by administration of melphalan and prednisolone. He was eventually discharged from the hospital two months after the surgery in fair condition.

\section{Discussion}

In the present case, IE was caused by S. salivarius. In a large series study, streptococcal species accounted for more than one half of documented IE (4). This group included a variety of species, such as S. mitior ( $25 \%$ of causes of IE on native valve), S. sangius ( $20 \%)$, S. mutans ( $10 \%)$, S. anginosus $(\sim 5 \%)$, and S. salivarius $(\sim 1 \%)(4,5)$. These organisms are normal inhabitants of oropharinx. On the other hand, transient bacteremias sporadically occur whenever an area heavily colonized with bacteria is traumatized. Transient bacteremias are most commonly associated with dental extraction, periodontal surgery, and oropharyngeal surgical procedures. Spontaneous bacteremia in the absence of trauma occurs with lung and skin infections 


\section{Multiple Myeloma with Endocarditis}

a

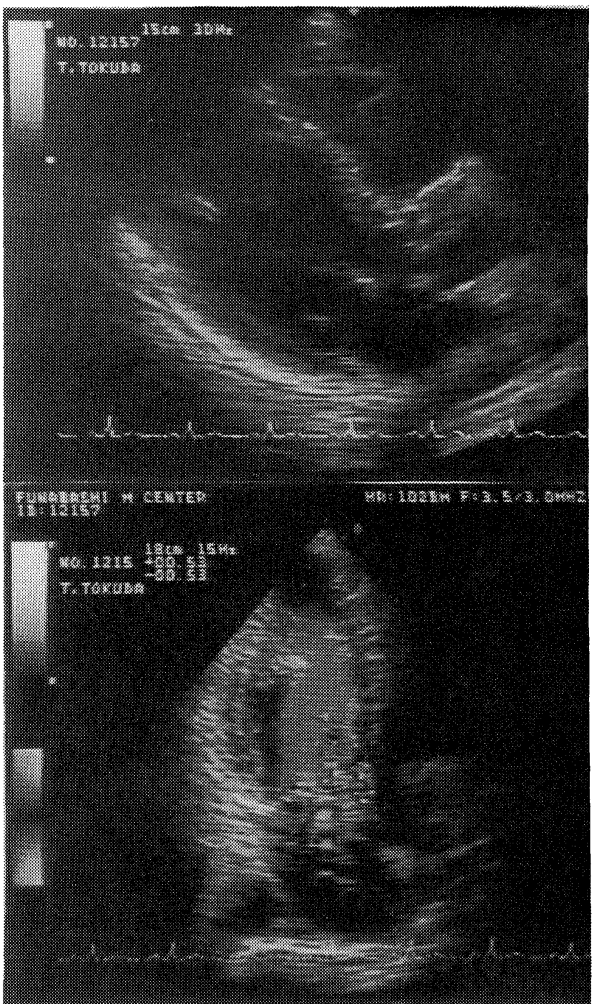

b

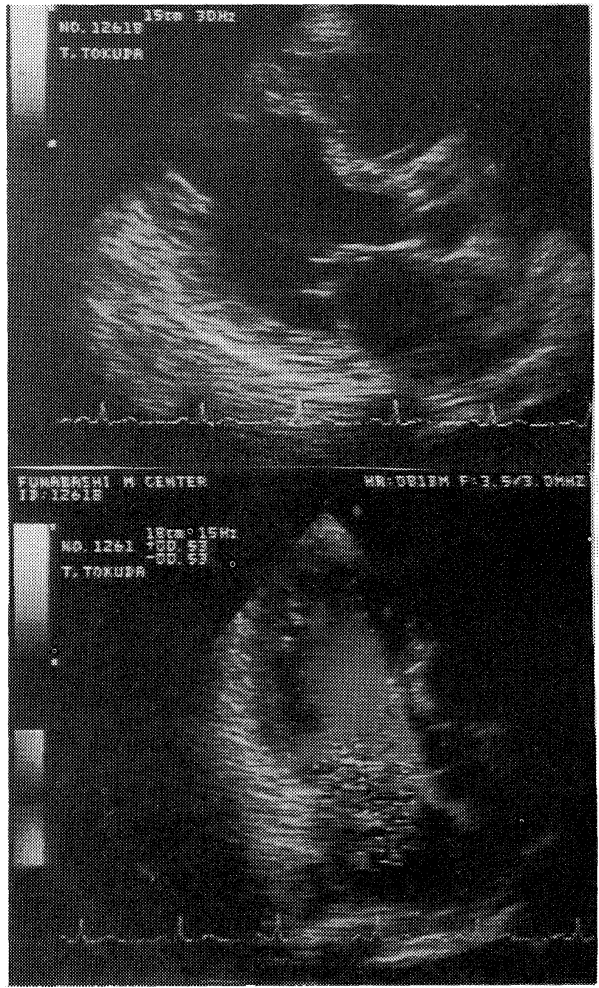

Long Axis View

Diastole

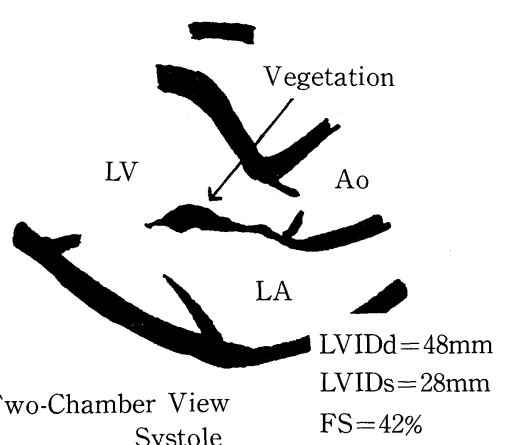

(Color

Doppler)

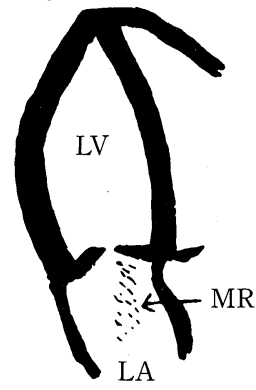

Long Axis View

Diastole

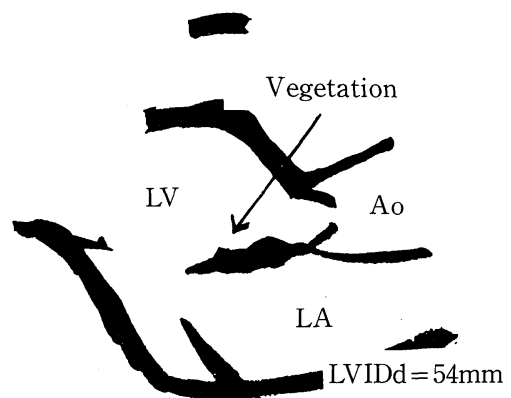

Two-Chamber View

Systole

(Color Doppler)

LVIDs $=31 \mathrm{~mm}$

$\mathrm{FS}=43 \%$

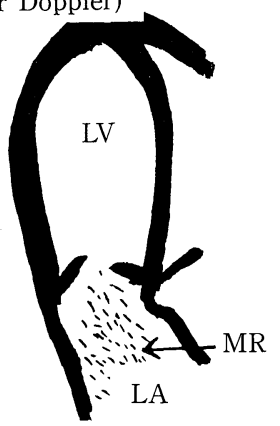

Fig. 2. Echocardiogram. (a) On admission, the slightly enlarged left ventricle and a vegetation on the anterior leaflet of the mitral valve were detected. Mitral regurgitation was shown by color flow doppler. (b) Two months later, enlargement of the vegetation as well as the presence of severe mitral regurgitation was demonstrated. Left ventricle was dilated larger than on admission. Ao: aorta, FS: fractional shortening = (LVIDd-LVIDs)/LVIDd, LA: left atrium, LV: left ventricle, LVIDd and LVIDs: left ventricular end-diastolic and end-systolic internal dimensions, MR: mitral regurgitation flow. 


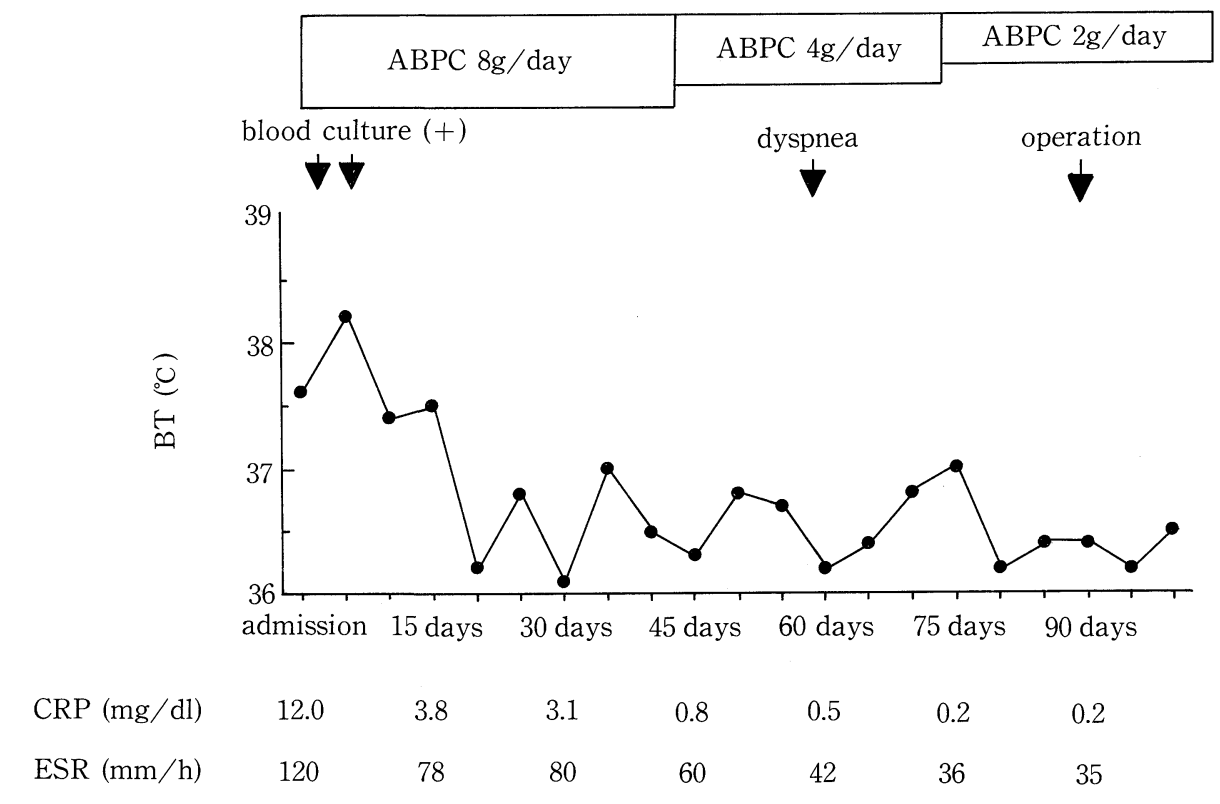

Fig. 3. Clinical course. The patient was treated with intravenous administration of aminobenzilpenicillin. The erythrocyte sedimentation rate and C-reactive protein were improved subsequently during the period of 6 weeks. However two months later, he developed a holosystolic murmur with the complaint of dyspnea on effort. He was scheduled for urgent surgery. ABPC: aminobenzilpenicillin, BT: body temperature, CRP: C-reactive protein, ESR: erythrocyte sedimentation rate.

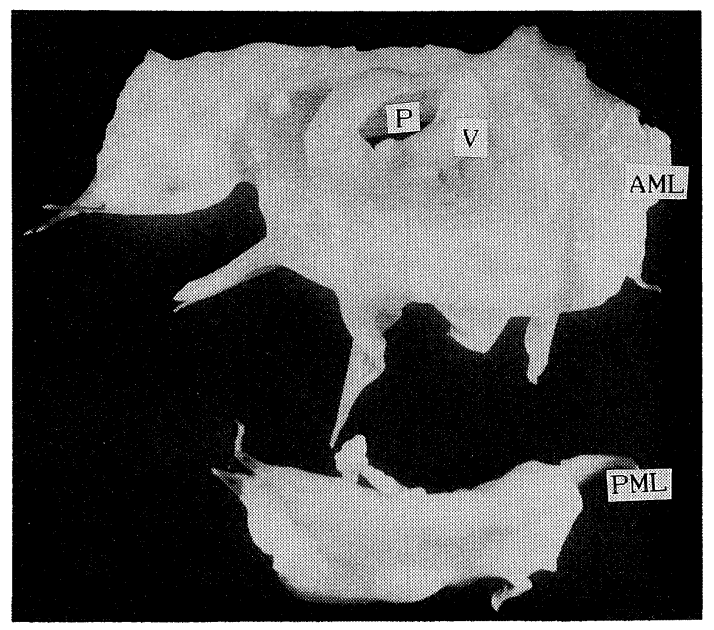

Fig. 4. Gross description of the specimen. A perforation with the healed vegetation on the anterior mitral leaflet was recognized. AML: anterior mitral leaflet, PML: posterior mitral leaflet, P: perforation, V: vegetation.

and in the patients with periodontal disease. A wide variety of trivial events (e.g. chewing and tooth brushing) are considered to be the source of streptococcal infection. The majority of the cases of streptococcal endocarditis are not related to iatrogenic procedures (6). In the present case, we suspected that the chronic gingivitis was the source of infection and that sponta- neous streptococcal bacteremia might have been caused in this condition by trivial events such as tooth brushing. As a consequence the vegetation was formed on the anterior mitral valve of which the prolapse to the left atrium had existed previously.

Infection in multiple myeloma occurs most often in an uncontrolled disease condition. A biphasic pattern of infection in this particular lesion has been reported (7). Episodes of streptococcus and hemophillus are frequently seen at the time of diagnosis as well as in the early months of the initiation of treatment. With the continuity of chemotherapy, a preponderance of gram-negative pathogens emerges in the course of prolonged treatment which leads to a major cause of death in patients. Infections with polysaccharide-encapsulated organisms such as streptococcus appear to be related to the functional hypogammaglobulinemia seen in multiple myeloma patients as well as a poor antibody response to antigenic stimulation $(8,9)$. The emergence of gram-negative bacilli as the major cause of infectious complications in myeloma correlates well with their role as the most common nosocomial infectious agents (10).

We reported a patient of multiple myeloma complicated with IE. IE is less likely to occur in multiple myeloma patients although bacteremia is a common complication in this disorder. In the recent studies, the incidence of IE ranged from $0.4 \%$ to $4.7 \%$ of bacteremia episodes with multiple myeloma per year $(3,10,11)$. This may be related to immunologic abnormalities inherent in plasma cell dyscreasis. The pathogenesis of IE involves a sterile platelet-fibrin thrombus on an endothelial surface, and a high titer of agglutinating antibody to the infecting organism. The platelet-fibrin thrombus evolves at the site of 
previous cardiac damage. The adherence of bacteria to these thrombi may be dependent on the presence of circulating specific bacterial antibodies especially agglutinins. Further, the contact between bacteria and platelets may result in further sequestration of large numbers of organisms within aggregated platelets $(12,13)$. Bacteria may either adhere passively to thrombi without prior interaction with circulating blood elements or alternatively bacterial agglutination with bacterial initiation of platelet clumping and phagocytosis of bacteremic organisms may be necessary for localization to the plateletfibrin thrombus. The immunologic phenomena characteristic of IE include B-cell hyper-responsiveness as manifested by elevated IgG and IgM levels and the presence of cryoglobulins, antinuclear antibodies, immune complexes and macroglobulins. On the other hand, in patients with multiple myeloma, normal plasma cells, functional antibodies, immune complexes and cardiac platelet-fibrin thrombi are decreased or absent, therefore they may be unable to develop sufficient bacterial clumping for valvular infection to occur.

Infectious complications with nosocomial agents are major concern in immunodeficient patients. However, one should be aware that polysaccharide encapsulated organisms, such as streptococcus and hemophillus, will infect multiple myeloma patients during their initial presentation of disease or clinical remission period. If IE by streptococcus or hemophillus is complicated in these stages, there is concern that it will be overlooked during diagnosis. Therefore, it is advisable that a patient is evaluated carefully to rule out any possibility of associated complication of infectious endocarditis under strict observation. When cardiac failure develops in the follow-up of the endocarditis, surgical repair such as valve replacement must be undertaken regardless to the stage of multiple myeloma.

In the present case, mitral valve replacement for severe mitral regurgitation was urgently undertaken and the postoperative course was in uneventful. This case may represent the first reported instance of a multiple myeloma patient complicated with IE and successfully treated by mitral valve replacement.

\section{References}

1) Zinneman HH, Hall WH. Recurrent pneumonia in multiple myeloma and some observations on immunologic response. Ann Intern Med 41: 1152, 1964.

2) Perri RT, Hebbel RP, Oken MM. Influence of treatment and response status on infection risk in multiple myeloma. Am J Med 71: 935, 1981.

3) Espersen F, Birgens HS, Hertz JB, Drivsholm A. Current patterns of bacterial infection in myelomatosis. Scand J Infect Dis 16: 169, 1984.

4) Roberts RB, Krigor AG, Schiller NL, et al. Viridans streptococcal endocarditis. The role of various species including pyridoxal-dependent streptococci. Rev Infect Dis 1: 955, 1979.

5) Coykendale AL. Classification and identification of the viridans streptococci. Clin Microbiol Rev 2: 315, 1989.

6) DurackDT. Current issues in the prevention of infective endocarditis. Am J Med 78 (Suppl B): 149, 1985.

7) Sawage DG, Lindenbaum J, Garret TJ. Biphasic pattern of bacterial infection in multiple myeloma. Ann Intern Med 96: 47, 1982.

8) Fahey JL, Scoggins R, Utz JP, et al. Infection, antibody response, and gamma globulin components in multiple myeloma and macroglobulinemia. Am J Med 35: 698, 1963.

9) Norden CW. Infections in patients with multiple myeloma. Arch Intern Med 140: 1150, 1980.

10) Meyer BR, Hirschman SZ, Axelrod JA. Current patterns of infection in multiple myeloma. Am J Med 52: 87, 1972.

11) Espersen F, Moller N, Rosdahl VT, Jessen O, Faber V, Rosendal K. Staphylococcus aureus bacteremia in patients with hematological malignancies and/or agranulocytosis. Acta Med Scand 222: 465, 1987.

12) Weinstein L, Schlesinger JJ. Pathoanatomic, pathophysiologic and clinical correlations in endocarditis. N Engl J Med 291: 832, 1974.

13) Plotkin GR. Multiple myeloma complicated by enterococcal endocarditis and penicillin allergy. J Ky Med Assoc 81: 88, 1983. 